\title{
Obituary
}

\section{Paulo Emílio Vanzolini (1924-2013)}

\section{Ulisses Caramaschi}

Universidade Federal do Rio de Janeiro, Museu Nacional - Departamento de Vertebrados. Quinta da Boa Vista, São Cristóvão, 20940-040, Rio de Janeiro, RJ, Brazil. E-mail: ulisses@acd.ufrj.br.

The Italian immigration to Brazil had its apex in the years 1878-1920. Among the immigrants was the physician G. Franco Grillo, follower of Giovanni Rossi (1856-1943), founder of the Cecília Colony, an anarchist initiative in the region of Palmeira, State of Paraná, in southern Brazil. The anarchism, based on the theory that formal government of any kind is unnecessary and wrong in principle, was followed in that colony between 1890-1894, when it was dissolved and the members returned to Italy or dispersed among several states of Brazil. Franco Grillo went to São Paulo and there his son Carlos Alberto Vanzolini (19031953) was born; he was given the family name of his grandfather, Giuliano Vanzolini, a Latinist who translated and published "De Rerum Natura" by Lucretius, from Latin verse to Italian verse in 1879, among other works.

Carlos Alberto Vanzolini graduated in Civil Engineering in the Polytechnic School of the University of São Paulo in 1925. He became Cathedra Professor of the Polytechnic School in 1943. A very formal and conventional man, he married Finoca Giudice Vanzolini, and the couple had three children, Paulo Emílio Vanzolini, the oldest child, Cláudio Eugênio Vanzolini, an engineer as was his father, and Maria Alice Silva da Leme, retired professor of psychology of the University of São Paulo.

Paulo Emílio Vanzolini came from an intellectual and academic family. He was born in

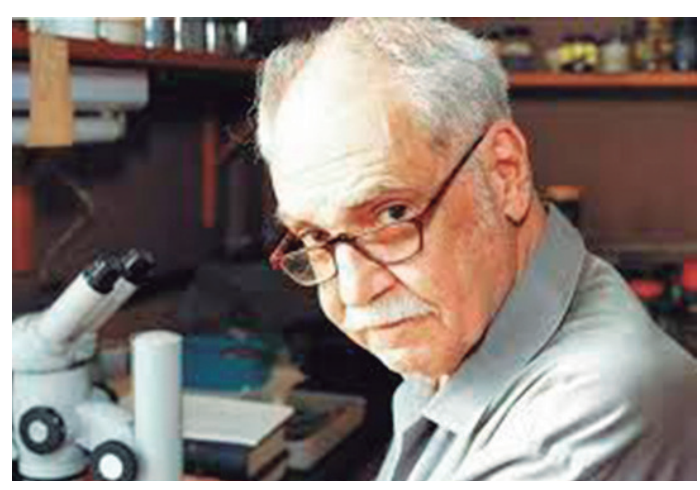

Source: $w w w 2 . i b . u s p . b r$.

the quarter of Cambuci, in the city of São Paulo (SP), on 25 April 1924 (although his official birth records have been dated from 25 April 1923, as seen in his military certificate published in the book "Tempos de Cabo de Paulo Vanzolini", in 1981). He lived from four to six years old in Rio de Janeiro (RJ), where his family moved to. His father was the engineer responsible for the construction of the traditional Institute of Education, in Tijuca. The family returned to São Paulo and Paulo Emílio studied in the National Lyceum Rio Branco, considered to be a very modern school. Later, he moved to the State Gymnasium, in the old downtown, because of better teaching. However, Paulo Emílio, as many over-medium intelligent children, hated school. In the old Brazilian educational system, a series of exams existed for the student to pass from one level to the next. At 
the age of 10 years, Paulo Emílio faced one of these exams to pass from the so called primary to the secondary level. Knowing that Paulo Emílio disliked school so much and would not study for the exams, his father told him that, if he passed the exam, he would receive a bicycle. The "suborn" worked, and Paulo Emílio passed the exam at the highest level and earned the desired bicycle. Having his own means of transportation, he cycled to the Instituto Butantan, located in the neighborhood where he lived. This was the first great decision in his life: amazed by the snake pits in Butantan, he promptly decided that he wished to be a scientist, to work on snakes. Pursuing his intent, Paulo Emílio rode his bike three times a week, each Monday, Wednesday, and Friday, when crates of live snakes arrived to Butantan by railway from all over State of São Paulo and even from several localities from the country, to be processed for antivenin production. He observed, and later assisted, the snake keepers to open the crates, lift out the snakes, identify each one, and select in which pit to place it. Paulo Emílio learned the popular and scientific names of the species received, obviously primarily poisonous snakes. Additionally, Paulo Emílio maintained his own live snake collection at his house, with his father's encouragement and tolerance of his mother.

A second event marked his decision when, in the early 1940's, his father presented him with a trip to Belém, in the State of Pará. Paulo Emílio visited the Museu Paraense Emílio Goeldi and contacted a group of professional collectors of butterflies who were embarking on a collecting excursion. He was invited and accepted to accompany them and this first contact with the Amazon Forest stimulated him to do professional and serious fieldwork in Amazonia in the future.

Paulo Emílio was created in a university ambience, having a good library at home, and appreciated and respected his father's work. When he was finishing the scientific level

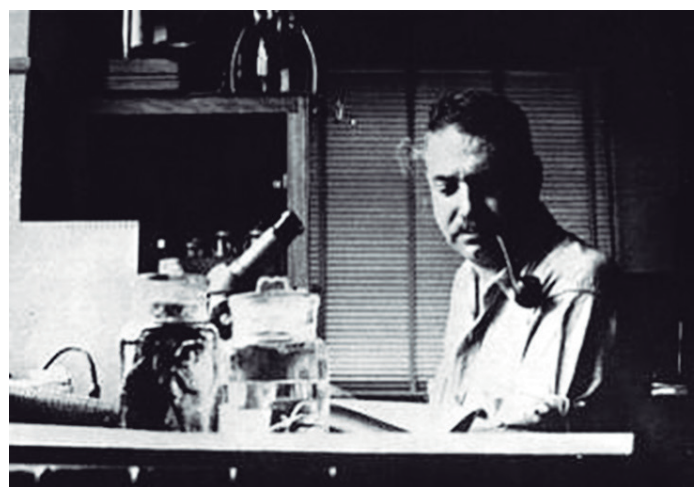

Source: www.canalciencia.ibict.br.

(equivalent to high school), in the beginning of the 1940's, he asked his father's advice on how to continue his studies to become a scientist specialized in herpetology. In turn, his father asked the advice of his colleague, Dr. André Dreyfuss (1897-1952), physician and geneticist, disciple of Theodosius Dobzhansky (19001975), and then Director of the Faculty of Philosophy, Sciences, and Letters (currently Institute of Biology) of the University of São Paulo. Dr. Dreyfuss, knowing that Paulo Emílio had serious interest about vertebrates, suggested that he avoid the natural history or biology course, because Dr. Ernst Marcus (1893-1968), head of zoology in the faculty and his staff were all invertebrate specialists and, worse, did not believe in evolution. Better would be the university medical school, where he would learn vertebrate anatomy and biology. He should then go to Europe or to the United States for a Ph.D. Paulo Emílio followed Dreyfuss's advice and, after a two-year pre-med program and six years of medical school, he graduated in medicine from the University of São Paulo in 1947. During the medical school period, Paulo Emílio had a brief political participation. As all other students at that time, he was against the Getúlio Vargas government; the repression to the students was severe and, by this epoch, he volunteered to the military service. During 1944-1945, contrary to 
all his fellow students, he didn't goes to the Preparatory Center for Reserve Officers (CPOR, in Brazilian abbreviation). He preferred to serve as a low rank soldier in the horse-mounted cavalry of the Brazilian Army, reaching the level of Corporal. In this epoch also developed his poet and composer vein, as he published a pamphlet entitled "Tempos de Cabo" (afterwards re-published in 1981 as "Tempos de Cabo de Paulo Vanzolini"; Palavra e Imagem Editora) with six poems, and he composed one of his more popular songs, "Ronda."

In November 1946, after completing his military service, Paulo Emílio was appointed as a biologist at the Museu de Zoologia of the State of São Paulo Secretary of Agriculture. Advanced degrees were not required for museum positions and his appointment was part time, a normal situation for new hires. Starting in his new museum position, the scientist Paulo Emílio Vanzolini revealed. He had to identify most of the 1200 specimens in the herpetological collection and, using Boulenger's catalogs to identify the species, he fell in love with the lizards. These animals would be his main research object during all his life.

Vanzolini was always contrary to the cathedra system of the University of São Paulo, a replication of the European system, where the full professor had a dictatorial position, made all other appointments, and the positions were served at his pleasure, many times without any concern of competence, but only to servility. On the other hand, he believed that the American university system, where tenured professors were hired in many fields of knowledge, provided a more thorough education. Therefore, he decided to apply to a university in the United States and, as thinking that he knew all that was to know about evolution, he wanted to go somewhere to learn about reptile anatomy. Again he followed advice from his father, who said to him: "Don't go to a university, go to a professor. Search for the better in the world and, if he

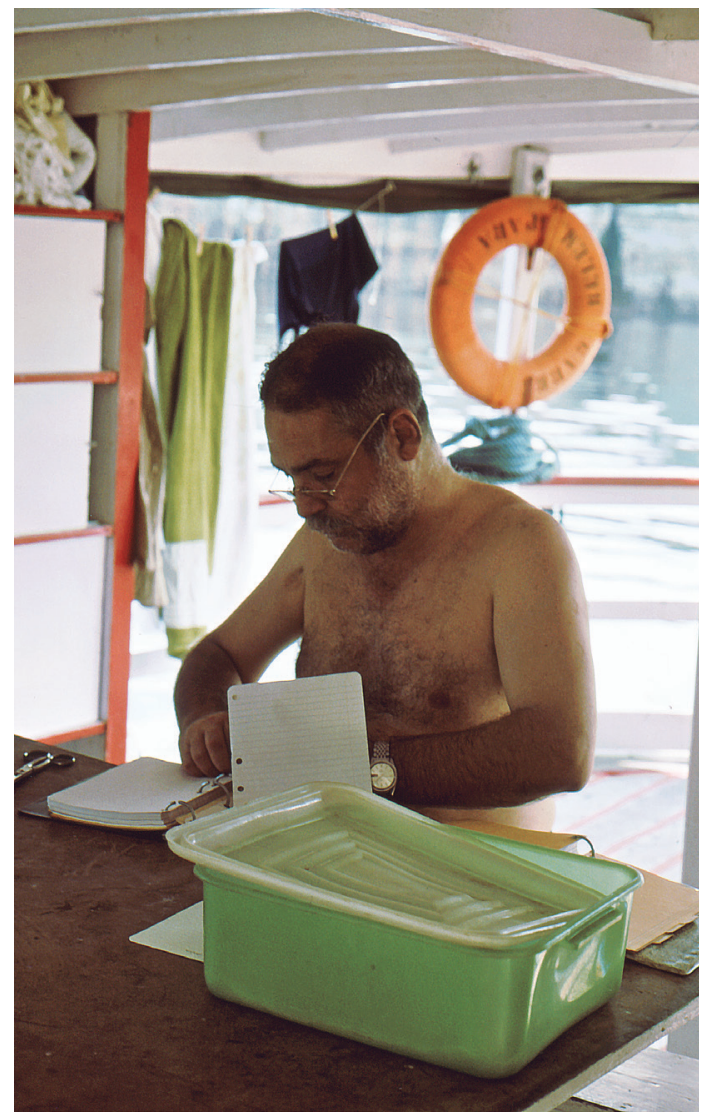

Vanzolini writing his field notes on the boat on the Rio Madeira (photo W. R. Heyer).

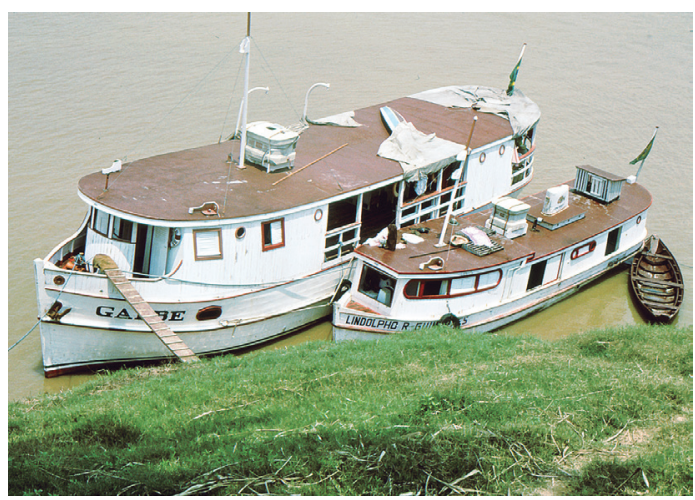

Vanzolini's boats, his pride and joy (photo W. R. Heyer). 
doesn't accept you, search for the second best." After that, he went to the library to find pertinent works and was very impressed by the papers of Alfred S. Romer (1894-1973), of Harvard University, Cambridge, Massachusetts. He wrote Romer asking if he could be his $\mathrm{PhD}$ student. Vanzolini always said: "The best accepted me, but up to this day I keep the letter that I wrote to him. It was a foolish letter - each time that I became vainer, I read that letter to put myself in my place". Vanzolini was and would be ever grateful to him for accepting his application.

Obtaining a paid leave of absence from the museum to obtain his PhD at Harvard as part of his training to become a curator at the Museu de Zoologia, Vanzolini went to United States in 1947. Once at Harvard, he completed his $\mathrm{PhD}$ in January 1951 in only five semesters, presenting the thesis entitled "Evolution, adaptations and distribution of the amphisbaenid lizards (Sauria, Amphisbaenidae)." He always again acknowledged the André Dreyfuss's advice, because his medical courses fulfilled almost all of Harvard's required courses. At Harvard, Vanzolini interacted with several outstanding scientists and found the general atmosphere stifling in that almost all of the students lived their lives centered on scientific activities, in contrast to the more bohemian environment he enjoyed in the University of São Paulo. A remarkable friendship was established with Ernst E. Williams (19141998), counted by Vanzolini as one of the most important in his life.

Returning to the Museu de Zoologia in São Paulo in 1952, Vanzolini re-assumed his duties, but he was still a part-time employee and had some debts from his graduate student years. He told his father he would have to find another job to supplement his part-time salary. His father considered that to be wasteful and offered him monthly financial aid so he could concentrate full-time on his museum work. However, soon after, his father was diagnosed with cancer and 14 months later, he died. During this time,
Vanzolini did not receive the financial aid and could not obtain extra work because he needed to attend to his father. His financial situation was very difficult after his father's death and, favored by his contacts in the artistic community, he was asked by a São Paulo television station (TV Record) to produce a weekly variety show. He said that, "By half hour a week, they pay me more than an entire month in the museum" and, after two years (1953-1954), he re-equilibrated his finances. After that, he obtained a full-time appointment at the museum and, after leaving the show producer activities, as museum employee he developed his entire professional career.

In 1959, as scientific advisor of the State of São Paulo Secretary of Agriculture, Vanzolini participated in the movement of professors and researchers that proposed the creation of a foundation to support research in the State of São Paulo. He was appointed to write the preproject for implementation and regulation for the new foundation by order of the at that time governor Carlos Alberto Alves de Carvalho Pinto (1910-1987) in his mandate between 1959 and 1963. Based on the structures of the northamerican Guggenheim and Ford Foundations, he established a modern system of management and maintenance of finances which basically stands to day. Therefore, the "Fundação de Amparo à Pesquisa do Estado de São Paulo" - FAPESP was created and currently it is one of the most important institutions for research support in the country. Paulo Emílio Vanzolini was member of the first High Council of FAPESP and council member in three administrations, in 1961-1967, 1977-1979, and 1986-1993.

Vanzolini, or only Vanzo for the scientific colleagues and as he wrote on the labels of specimens as collector or identifier - or, further, simply Paulinho in the artistic environment was appointed Director of the Museu de Zoologia in 1962. In this position he stayed during 31 years, right up to his obligatory retirement, at 70 
years old, in 1993. After his retirement he was designated Professor Emeritus of the São Paulo University. During all this time he was as ever involved in the day-to-day duties curating the reptile and amphibian collections (and even occasionally of birds and mammals), besides the administrative incumbencies.

In 1969 Vanzolini supported the transference of the Museu de Zoologia from the Secretary of Agriculture to the São Paulo University. In this way, the institution would participate in the intellectual academic community and its employees would be themselves involved in activities of undergraduate and graduate teaching and guidance. Vanzolini himself was advisor to 38 doctoral students in the São Paulo University, in several areas of knowledge.

Vanzolini was elected permanent member of the Brazilian Academy of Sciences in 1963. Although he was not an assiduous participant in reunions, he participated in important tasks in terms of publications and scientific expeditions, mainly during the 15 years when his friend Aristides Pacheco Leão (1914-1993) was President of the Academy.

Paulo Emílio Vanzolini was always fascinated by the Amazon, which he visited the first time in the 1940's. He made several trips to the region, but the main initiative which he undertook part was the "Expedição Permanente à Amazônia (EPA)" ("Permanent Expedition to Amazon"). Under his supervision, two boats named "Garbe" and "Lindolpho Guimarães" served as bases for accommodation and laboratory, with support of two canoes for shorter incursions. From 1966 to 1975, the EPA covered large number of rivers, lakes, and rivulets in the Amazon, obtaining an immense amount of specimens for all collections of the Museu de Zoologia. Besides the collections, Vanzolini was also avid in obtaining collections of specimens and books. He normally applied money obtained through his songs to purchase specimens and rare and expensive books. His herpetological library was virtually complete respecting the South American herpetology and normally with first editions. Vanzolini continued to work assiduously in the Museu de Zoologia even after his obligatory retirement. In 2008, after the donation of his books, reprints, maps, and other bibliographical items to the Museu de Zoologia library, he stopped attending the Museu de Zoologia, but dedicated to his second passion: Brazilian popular music. He usually said that he did not like to do shows, but greatly appreciated attending them.

His last public appearance was in the Oficina Theater, in São Paulo, in March 2013, during a beneficent event. In the same month, he received the APCA Premium (São Paulo Association of Art Critics Premium), in recognition of his musical work. The composer climbed the stage to receive this trophy on a wheel chair and the audience gave him standing ovation. On the scientific side, besides being a member of the Brazilian Academy of Sciences, he was distinguished by the Guggenheim Foundation (1949), in New York, USA, by his contribution to the science progress, designated an Honorary Foreign Member of the American Association of Ichthyologists and Herpetologists (1973), honored by the Great Cross of the National Scientific Merit Order, in Brazil (1994), received a Merit Honor Diploma from the Brazilian Society of Zoology (2000), the Rio Branco Order (2002), the Commendan of the Ipiranga Order (2003), the Rocha Lima Medal of the Biological Institute of São Paulo (2004), the title of Emeritus Researcher of the National Council of Scientific Development (CNPq, 2007), and the Anchieta Medal (2009). He was also awarded the Conrado Wessel Prize in the category "Culture" (2011). Vanzolini had two genera of lizards and 14 species (including reptiles, amphibians, primates, spiders, diplopods, and insects) named after him.

On 25 April 2013, on his 89 birthday, Paulo Emílio Vanzolini was hospitalized in the intensive 
care unit of the Albert Einstein Israelite Hospital, in São Paulo. Victim of extensive pneumonia, he passed the weekend sedate and unconscious, and died at 23:35 hs on the day 28 April 2013, at 89 years old. He was buried in the Consolação Cemetery, in São Paulo, at 16:40 hs of 29 April 2013. With his first wife, Ilse Vanzolini, he had six children. His first son, José Henrique, died tragically in a car accident at 11 years old. His second daughter, Maria Eugênia, psychologist, is married and has three daughters, one of whom is the mother of his one great grandchild; third, Mariana, an anthropology museum conservation technician; fourth, Maria Emília, a geography teacher with four children; fifth, Fernanda, a lawyer with two children; and finally, Antonio Pedro, a distinguished film director. In second nuptials, he got married to the singer Ana Bernardo, who accompanied him to his death.

Acknowledgment - Thanks to Ron Heyer for the English review and photographs.

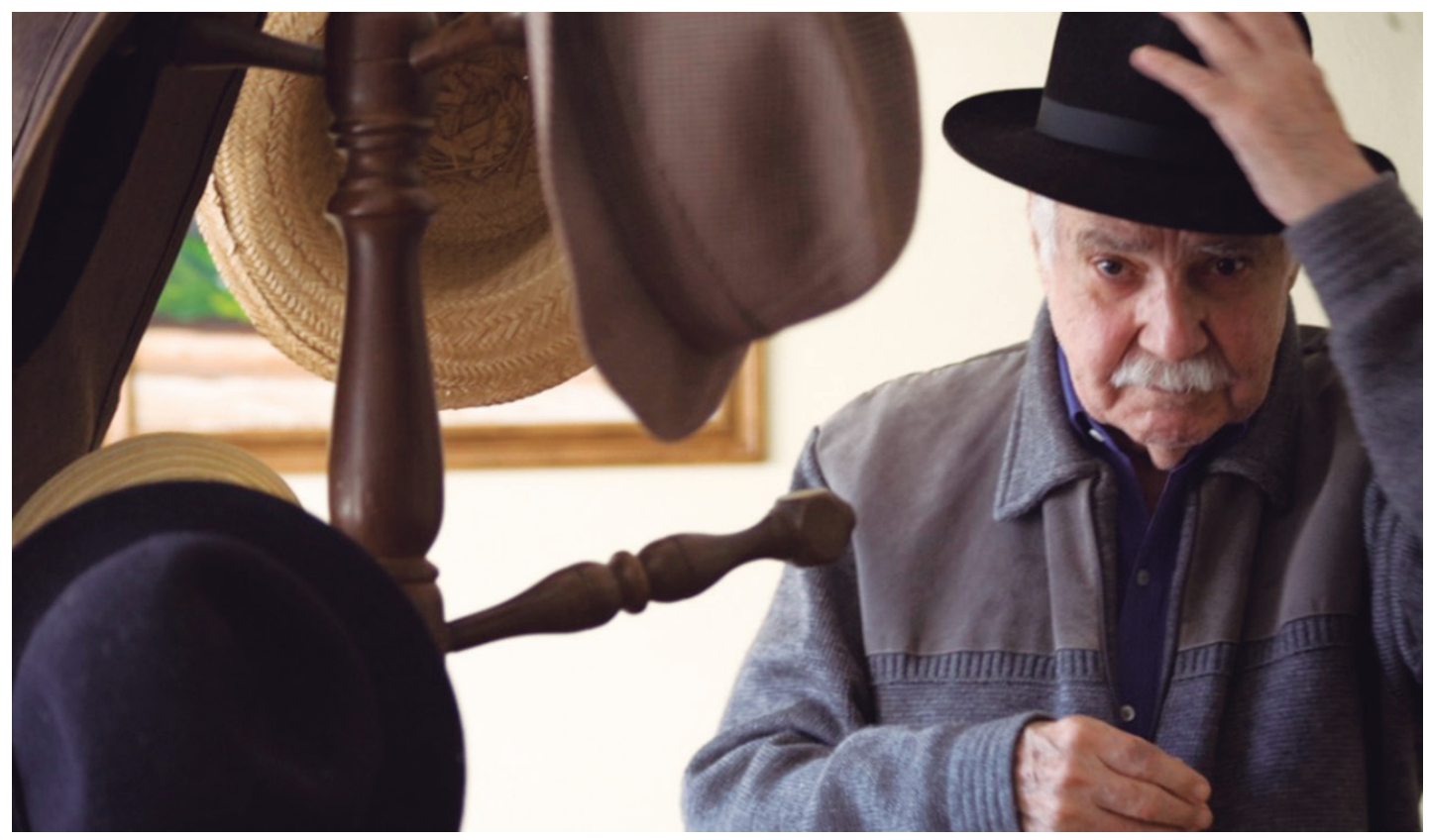

Source: www.brasil247.com. 